\title{
Survey of causative agents for acute respiratory infections among patients in Khartoum- State, Sudan, 2010-2011
}

\author{
Khalid A Enan', Takeshi Nabeshima², Toru Kubo², Corazon C Buerano ${ }^{3}$, Abdel Rahim M El Hussein ${ }^{4}$, \\ Isam M Elkhidir ${ }^{5}$, Eltahir AG Khalil ${ }^{6}$ and Kouichi Morita ${ }^{2 *}$
}

\begin{abstract}
Background: This study was carried out to determine causative agents of acute respiratory illness of patients in Khartoum State, Sudan.

Methods: Four hundred patients experiencing respiratory infections within January-March 2010 and January-March 2011 were admitted at Khartoum Hospital and had their throat swab samples subjected to multiplex real-time RT-PCR to detect influenza viruses (including subtypes) and other viral agents. Isolation, nucleotide sequence and phylogenetic analysis on some influenza viruses based on the HA gene were done.

Results: Out of 400 patients, 66 were found to have influenza viruses $(35,27,2$, and 2 with types A, B, C, and A and B co-infections, respectively). Influenza viruses were detected in 28,33 and 5 patients in the age groups $<1,1-10$, and 11-30 years old, respectively but none in the 31-50 years old group. Out of 334 patients negative for influenza viruses, 27, 14, and 2 were positive for human respiratory syncytial virus, rhinovirus and adenovirus, respectively. Phylogenetic tree on influenza A (H1N1) pdm09 subtype shows that Sudan strains belong to the same clade and are related to those strains from several countries such as USA, Japan, Italy, United Kingdom, Germany, Russia, Greece, Denmark, Taiwan, Turkey and Kenya. Seasonal A H3 subtypes have close similarity to strains from Singapore, Brazil, Canada, Denmark, USA and Nicaragua. For influenza B, Sudan strains belong to two different clades, and just like influenza A (H1N1) pdm09 and A H3 subtypes, seem to be part of worldwide endemic population (Kenya, USA, Brazil, Russia, Taiwan and Singapore).
\end{abstract}

Conclusions: In Sudan, the existence of respiratory viruses in patients with acute respiratory infection was confirmed and characterized for the first time by using molecular techniques.

Keywords: Influenza viruses, Human respiratory syncytial virus, Rhinovirus, Adenovirus, Epidemiology, Sudan

\section{Background}

Influenza and other respiratory tract infecting viruses are a common cause of upper and lower respiratory tract infection and are responsible for morbidity and mortality especially in the elderly and in high-risk groups such as immunocompromised patients and those with chronic diseases [1,2]. Influenza viruses have been well studied in developed countries. However, the epidemiology of influenza and the hospitalization rates associated with the

\footnotetext{
*Correspondence: moritak@nagasaki-u.ac.jp

${ }^{2}$ Department of Virology, Institute of Tropical Medicine, Nagasaki University, Nagasaki 852-8523, Japan

Full list of author information is available at the end of the article
}

illness may be different in sub-Saharan Africa for several reasons $[3,4]$.

Meager information is available on the epidemiology of influenza in Sudan. This is mainly due to lack of laboratory facilities and expertise. Influenza is also perceived as a mild disease in a country like Sudan where other causes of fever such as malaria, kala azar, and typhoid are highly prevalent [5]. The first isolation of influenza virus in Sudan was carried out by Salim in 1970, who reported on the isolation of haemagglutinating agents from throat gargles by using chicken embryos [5].

Although, surveillance data from the African continent has increased substantially in the past five years, they are

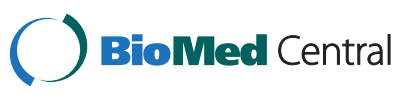


inadequate to allow for a thorough understanding of influenza virus circulation patterns on the continent and their associated morbidity and mortality, or to provide information for influenza control strategies [6]. In the Afriflu meeting that was held in June 2010 in Marrakesh, Morocco, influenza specialists and public health experts pledged to follow concrete measures to bridge the knowledge gap on the burden of influenza in Africa [6]. One of the key measures recommended was the reinforcement of routine influenza surveillance capacity both from an epidemiological and a virological standpoints.

The present study aimed to identify human influenza viruses circulating in Sudan from January to March 2010 and January to March 2011, periods at which high incidence of acute respiratory infections are usually recorded [5]. This was accomplished by subjecting throat swab samples taken from suspected influenza patients to multiplex real-time RT-PCR and subjecting some identified influenza viruses for nucleotide sequence. Samples negative for influenza viruses were then tested for other common respiratory tract-infecting viruses namely human respiratory syncytial virus (RSV), human metapneumovirus (hMPV), rhinovirus, and adenovirus.

\section{Results}

\section{Influenza viruses and other respiratory viruses}

During the study period, 400 patients were enrolled. Three hundred and sixty eight 368 (92\%) were children between the ages of $<1$ and 10 years. The median length of hospitalization was 2 days. Influenza viruses were detected in $66(16.5 \%)$ patients (Table 1). Out of 66 patients, 35 (53.0\%) were detected with influenza type A virus, 27(40.9\%) with influenza type B, 2 (3\%) with influenza type $\mathrm{C}$ and $2(3 \%)$ with a co-infection of influenza types $\mathrm{A}$ and $\mathrm{B}$. Out of the 37 patients positive for influenza A due to single or co-infection, 28 (75.7\%) were infected with $\mathrm{A}(\mathrm{H} 1 \mathrm{~N} 1)$ pdm09, 8 (21.6\%) with H3 subtypes and $1(2.7 \%)$ unsubtypeable. While both subtypes were detected from patients during 2011 collections, no subtype H3 was detected in 2010 collections (Table 2).

Out of 334 patients that were negative for influenza viruses, 43 (13\%) were found positive for other respiratory viruses. Out of these positives, 27(62.8\%), 14 (32.6\%), and 2 (4.6\%) had RSV, rhinovirus and adenovirus infections, respectively (Table 3 ). No patient was found positive for hMPV.

Based on age group, the distribution of 66 patients positive for influenza viruses were 28 (42.4\%), $33(50 \%)$, and 5 $(7.6 \%)$ in age groups $<1$ year, $1-10$ years, and $11-30$ years old, respectively (Table 1 ). No influenza viruses were detected from patients in age group 31-50 years old. Out of the 28 patients from the age group $<1$ year, 19,8 , and 1 patients were infected with type A, B and C, respectively. From this age group, the results of detecting other respiratory viruses from patients negative for influenza viruses, showed that $17(81 \%)$ and 4 (19\%) patients were positive for RSV, and rhinovirus, respectively (Table 3 ). In age group 1 - 10 years old, a total of 204 samples (Table 1) were screened and of the 33 patients who proved positive for influenza, 13, 17, 1, and 2 had type A, type B, type C and a co-infection of types A and B respectively. From patients negative for influenza virus and belonging to the age group $1-10$ years, a total of 20 patients were found positive for other respiratory viruses: nine were positive for RSV , nine for rhinovirus and two for adenovirus (Table 3).

From patients of the age group 11 - 30 years, three samples were positive for influenza type A and two for influenza type B (Table 1). From patients of this same age group, negative samples for influenza virus were tested for other respiratory viruses and one patient was found positive for RSV and one for rhinovirus (Table 3). From the age group 31 to 50, no sample was found positive for influenza and other respiratory viruses (Tables 1 and 3).

According to the gender, influenza viruses were detected in 39 (59\%) male and 27 (41\%) female patients. Other respiratory viruses were detected in 23 (53.5\%) male and in 20(46.5\%) female patients (Table 4).

Table 1 Total number of patients by age and the distribution of influenza viruses in 66 patients

\begin{tabular}{|c|c|c|c|c|c|c|c|}
\hline \multicolumn{8}{|c|}{ Number of patients with influenza viruses (\%) } \\
\hline Age group in years & Number of patient (\%) [\%] ${ }^{1}$ & A & B & C & $A B$ & Total negative (\%) & Total positive (\%) [\%] ${ }^{2}$ \\
\hline$<1$ & $164(100)[41.0]$ & $19(54.3)$ & $8(29.6)$ & $1(50.0)$ & $0(0)$ & $136(82.9)$ & $28(17.1)[42.4]$ \\
\hline $1-10$ & $204(100)[51.0]$ & $13(37.1)$ & $17(63.0)$ & $1(50.0)$ & $2(100)$ & $171(83.8)$ & $33(16.2)[50.0]$ \\
\hline $11-30$ & $27(100)[6.8]$ & $3(8.6)$ & $2(7.4)$ & $0(0)$ & $0(0)$ & $22(81.5)$ & $5(18.5)[7.6]$ \\
\hline $31-50$ & $5(100)[1.2]$ & $0(0)$ & $0(0)$ & $0(0)$ & $0(0)$ & $5(100)$ & $0(0)$ \\
\hline Total & $400(100)[100]$ & $35(8.8)\{53.0\}^{3}$ & $27(6.8)\{40.9\}$ & $2(0.5)\{3.0\}$ & $2(0.5)\{3.0\}$ & $334(83.5)$ & $66(16.5)[100]\{100\}$ \\
\hline
\end{tabular}

${ }^{1}$ Percent inside bracket found on the second column is \% out of 400 patients.

${ }^{2}$ Percent inside bracket found on the last column is \% out of 66 patients.

${ }^{3}$ Percent inside curly bracket found on the last row is \% out of 66 patients. 
Table 2 Number of patients with influenza viruses detected in 2010 and 2011

\begin{tabular}{|c|c|c|c|c|c|c|c|c|c|}
\hline \multirow[t]{2}{*}{ Year } & \multicolumn{4}{|c|}{ Number of patients with influenza viruses } & \multirow{2}{*}{$\begin{array}{l}\begin{array}{l}\text { Total number of } \\
\text { patients with }\end{array} \\
\text { Influenza } A, B, C\end{array}$} & \multirow{2}{*}{$\begin{array}{l}\begin{array}{l}\text { Total number of } \\
\text { patients with }\end{array} \\
\text { Influenza A }\end{array}$} & \multicolumn{3}{|c|}{$\begin{array}{l}\text { Number of patients with specific } \\
\text { subtype of influenza A }\end{array}$} \\
\hline & A & B & $\mathrm{C}$ & $A B$ & & & A (H1N1) pdm09 & $\mathrm{H} 3$ & Unsubtypeable \\
\hline 2010 & 4 & 8 & 0 & 0 & 12 & 4 & 4 & 0 & 0 \\
\hline 2011 & 31 & 19 & 2 & 2 & 54 & 33 & 24 & 8 & 1 \\
\hline Total & 35 & 27 & 2 & 2 & 66 & 37 & 28 & 8 & 1 \\
\hline
\end{tabular}

\section{Nucleotide sequence and phylogenetic analysis of influenza viruses}

Successful sequence of $\mathrm{H} 1$ of $\mathrm{A}(\mathrm{H} 1 \mathrm{~N} 1)$ pdm09 subtype, influenza type A H3 and influenza type B based on HA gene was done on 20 samples-10 samples of $A(H 1 N 1)$ pdm09, 2 samples of $\mathrm{H} 3$ and 8 samples of influenza type B-with the RNA template either directly from throat swab samples or from virus isolates (8 isolates) present in infected culture fluid (Table 5). The nucleotide sequences were compared with other sequences published in GenBank. Phylogenetic trees that were generated for the $\mathrm{H} 1$ of $\mathrm{A}(\mathrm{H} 1 \mathrm{~N} 1)$ pdm09, influenza types $\mathrm{A} \mathrm{H} 3$ and influenza virus type B are shown in Figures 1, 2 and 3, respectively, and the aligned sequences of Sudan strains in fasta format are found in the additional materials (Additional files 1, 2 and 3). The phylogenetic tree on $\mathrm{H} 1$ (Figure 1; Additional file 4 for actual phylogenetic tree) shows that they belong to the same clade and are related to several strains from around the world (USA, Japan, Italy, United Kingdom, Germany, Russia, Greece, Denmark, Taiwan, Turkey and Kenya). Seasonal H3 subtypes detected only during the 2011 season have close similarity to strains from several parts of the world (Singapore, Brazil, Canada, Denmark, USA and Nicaragua; Figure 2, Additional file 5) also. The phylogenetic tree for the influenza B (Figure 3) shows two different populations of this virus in Sudan strains detected in 2011 and these populations are related to the strains in Kenya, USA, Brazil, Russia, Taiwan and Singapore.

\section{Discussion and conclusion}

Little is known about the epidemiology of influenza viruses in Sudan in particular and in Africa in general. As

Table 3 Patients grouped by age and detected with other respiratory viruses

\begin{tabular}{llllll}
\hline \multirow{2}{*}{$\begin{array}{l}\text { Age group } \\
\text { in years }\end{array}$} & \multicolumn{4}{c}{ Number of patients (\%) } & \\
\cline { 2 - 5 } & RSV & hMPV & Rhinovirus & Adenovirus & Total \\
\hline$<1$ & $17(81.0)$ & $0(0)$ & $4(19.0)$ & $0(0)$ & $21(48.9)$ \\
$1-10$ & $9(45.0)$ & $0(0)$ & $9(45.0)$ & $2(10.0)$ & $20(46.5)$ \\
$11-30$ & $1(50.0)$ & $0(0)$ & $1(50.0)$ & $0(0)$ & $2(4.6)$ \\
$31-50$ & $0(0)$ & $0(0)$ & $0(0)$ & $0(0)$ & $0(0)$ \\
Total & $27(62.8)$ & $0(0)$ & $14(32.6)$ & $2(4.6)$ & $43(100)$ \\
\hline
\end{tabular}

a consequence, authorities in countries located just on either side of the equator in the sub-Sharan Africa find it difficult to decide which influenza vaccine to choose: the northern hemisphere or the southern hemisphere $[7,8]$. In Sudan, no regular program of vaccination against seasonal influenza is being implemented [9]. For the 2013-2014 northern hemisphere influenza season [7] and the 2013 southern hemisphere influenza season [8], World Health Organization recommended that the composition of trivalent vaccines include an A/California/ 7/2009 (H1N1) pdm09-like virus and in addition other viral components that are specific only for each type e.g. a B/Massachusetts/2/2012-like virus for the northern hemisphere vaccine and B/Wisconsin/1/2010-like virus for southern hemisphere vaccine. Hence, there is a need to know the type of influenza viruses occurring in a particular geographical area, especially in those areas with uncertain boundaries, to serve as a guide in choosing a specific type of vaccine. Through surveillance in sentinel hospitals, data can be provided for describing influenza epidemiology and seasonality, for characterizing circulating strains of influenza virus to serves as a basis in selecting the right type of vaccine and for monitoring influenza pandemics [10].

Table 4 Patients with acute respiratory infection, classified as to gender and the respiratory virus

\begin{tabular}{llll}
\hline Virus detected & \multicolumn{2}{c}{ Number (\%) } & Total \\
\cline { 2 - 3 } & Male & Female & \\
\hline Influenza viruses & 19 & 16 & 35 \\
Influenza A & 16 & 11 & 27 \\
Influenza B & 2 & 0 & 2 \\
Influenza A and B & 2 & 0 & 2 \\
Total & $39(59.0)$ & $27(41.0)$ & $66(100)$ \\
Other respiratory viruses & & & 27 \\
RSV & 13 & 14 & 0 \\
hMPV & 0 & 0 & 14 \\
Rhinovirus & 8 & 6 & 2 \\
Adenovirus & 2 & 0 & $43(100)$ \\
Total & $23(53.5)$ & $20(46.5)$ &
\end{tabular}


Table 5 Influenza viruses that were sequenced and related information

\begin{tabular}{|c|c|c|c|c|}
\hline Strain name & Date of collection & Age & Sex & GenBank accession number \\
\hline A/Sudan/99/2011 (H1) & 2011-01-20 & $2 \mathrm{mo}$ & M & KF150680 \\
\hline A/Sudan/98/2011 (H1) & 2011-01-20 & $8 \mathrm{mo}-4 \mathrm{~d}$ & M & KF150679 \\
\hline A/Sudan/136/2011 (H1) & 2011-01-30 & $6 \mathrm{mo}$ & $\mathrm{F}$ & KF150674 \\
\hline A/Sudan/126/2011 (H1) & $2011-01-26$ & $9 \mathrm{mo}$ & M & KF150673 \\
\hline A/Sudan/119/2011 (H1) & $2011-01-22$ & $3 \mathrm{mo}$ & M & KF150672 \\
\hline A/Sudan/91/2011 (H1) & 2011-01-21 & $8 \mathrm{mo}$ & $\mathrm{F}$ & KF150678 \\
\hline A/Sudan/116/2011 (H1) & $2011-01-22$ & $6 \mathrm{yr}$ & $\mathrm{F}$ & KF150671 \\
\hline A/Sudan/175/2011 (H1) & 2011-02-01 & $2 \mathrm{mo}$ & $\mathrm{F}$ & KF150675 \\
\hline A/Sudan/238/2011 (H1) & $2011-02-14$ & $4 y r-5$ mo & $\mathrm{F}$ & KF150677 \\
\hline A/Sudan/229/2011 (H1) & $2011-02-13$ & $4 y r-8 \mathrm{mo}$ & $\mathrm{F}$ & KF150676 \\
\hline A/Sudan/95/2011* $(\mathrm{H} 3)$ & 2011-01-20 & $5 \mathrm{yr}$ & M & KF150681 \\
\hline A/Sudan/105/2011 (H3) & 2011-01-22 & $2 \mathrm{mo}$ & M & KF150682 \\
\hline B/Sudan/134/2011 & 2011-01-30 & $10 \mathrm{yr}$ & M & KF150684 \\
\hline B/Sudan/118/2011 & $2011-01-22$ & $7 d$ & M & KF150683 \\
\hline B/Sudan/84/2011 & 2011-01-19 & $11 \mathrm{yr}$ & M & KF150688 \\
\hline B/Sudan/87/2011 & 2011-01-19 & $4 \mathrm{mo}$ & $\mathrm{F}$ & KF150689 \\
\hline B/Sudan/94/2011 & 2011-01-20 & $5 \mathrm{yr}$ & M & KF150690 \\
\hline B/Sudan/186/2011 & 2011-02-06 & $4 \mathrm{mo}$ & M & KF150685 \\
\hline B/Sudan/226/2011 & 2011-02-13 & $1 \mathrm{yr}-1 \mathrm{mo}$ & $\mathrm{F}$ & KF150686 \\
\hline B/Sudan/227/2011 & $2011-02-13$ & $5 \mathrm{mo}$ & M & KF150687 \\
\hline
\end{tabular}

*Source of the virus also contained influenza B.

Our current study in Sudan is one of the first to report directly-measured rates of influenza-associated hospitalization in adults and children. The study revealed that influenza types $\mathrm{A}, \mathrm{B}$ and $\mathrm{C}$ were circulating in Sudan, and were detectable in $16.5 \%$ of the patients. Types A and B were responsible for most of the influenza infections. The subtype influenza A(H1N1)pdm09 was detected in $75.7 \%$ of the patients with influenza A infection. Type $\mathrm{C}$ was detected in patients only during the 2011 season. Influenza virus infections were detected in all age group examined but with the exception of the oldest group (30-50 years). Infection was recorded mostly in the young age groups $(<1$ year, $1-$ 10 years). Taken all of the above findings into consideration, these may indicate complex epidemiology of influenza viruses in Sudan. Similar results were recorded in Nigeria, where all 3 types of influenza viruses were also detected [11]. A study conducted in Sudan during two periods (December 1987 to April 1988 and September 1990 to March 1991) reported the detection of influenza A (or B) in four out of 213 (2\%) children by using either immunofluorescence assay for antigen detection or ELISA [12].

Phylogenetic analysis of $\mathrm{H} 1$ of $\mathrm{A}(\mathrm{H} 1 \mathrm{~N} 1) \mathrm{pdm} 09$ subtypes in this study indicated that they belong to the same clade and that they were related to the strains in the USA, Japan, Italy and other several countries.
Seasonal influenza A H3 subtypes were similar to strains from Singapore as well as from other parts of the world. Influenza B strains from Sudan belong to two different world-wide distributed clades. This pattern suggests that Sudan strains were a part of worldwide endemic population.

Other respiratory viruses including RSV, rhinovirus and adenovirus were also found to cause respiratory infection mostly (95.4\%) in the younger age groups ( $<1$ year, $1-10$ years). Infection by RSV and adenovirus among Sudanese children was also reported previously [12]. Interestingly, no hMPV was detected in the present study; this virus has been detected in other countries in Africa including Kenya [13] and Nigeria [11]. These findings highlight the need for the establishment in Sudan of rapid, sensitive, and specific diagnostic techniques (such as ones used here) for better management of respiratory infections especially in the high risk groups (infants, elderly and immunocompromised patients).

To our knowledge this is the first attempt to identify the causative viral agents of respiratory infections in Sudan by using molecular techniques and to characterize influenza viruses specifically. Finally, the results obtained should call for wider surveillance at the national level in order to fully elucidate the true status and epidemiology of influenza viruses in Sudan. 


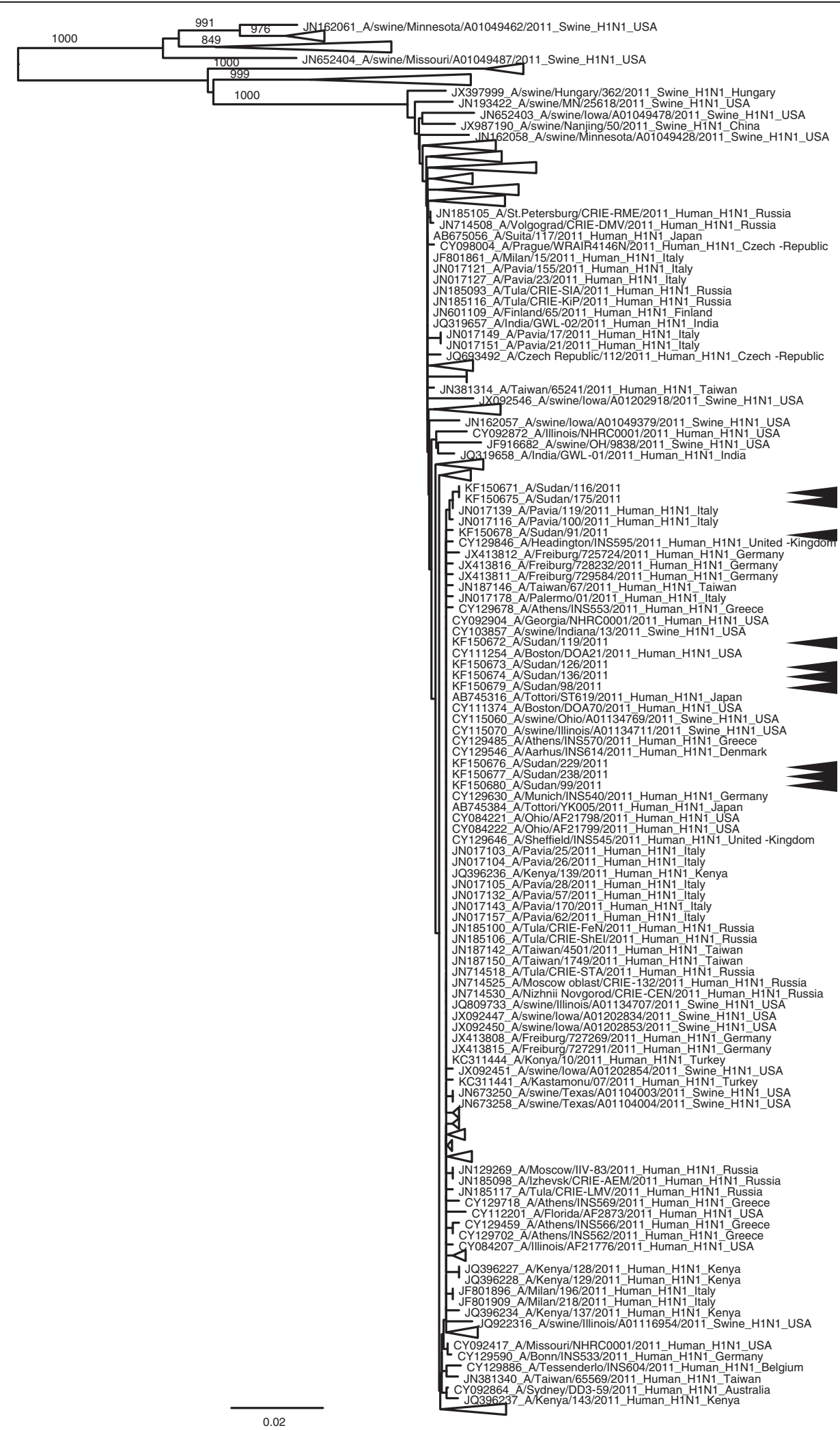

Figure 1 Phylogenetic tree of HA1 gene of influenza A strains from Sudan. Tree was constructed from representative strains detected in 2011. Some branches were collapsed for clarity. The actual tree with all the strains can be viewed in Additional file 4 and the strains in the expanded branches are indicated by green lines. Bootstrap values (1000 times) are shown at the nodes. Arrowheads indicate strains from Sudan. 


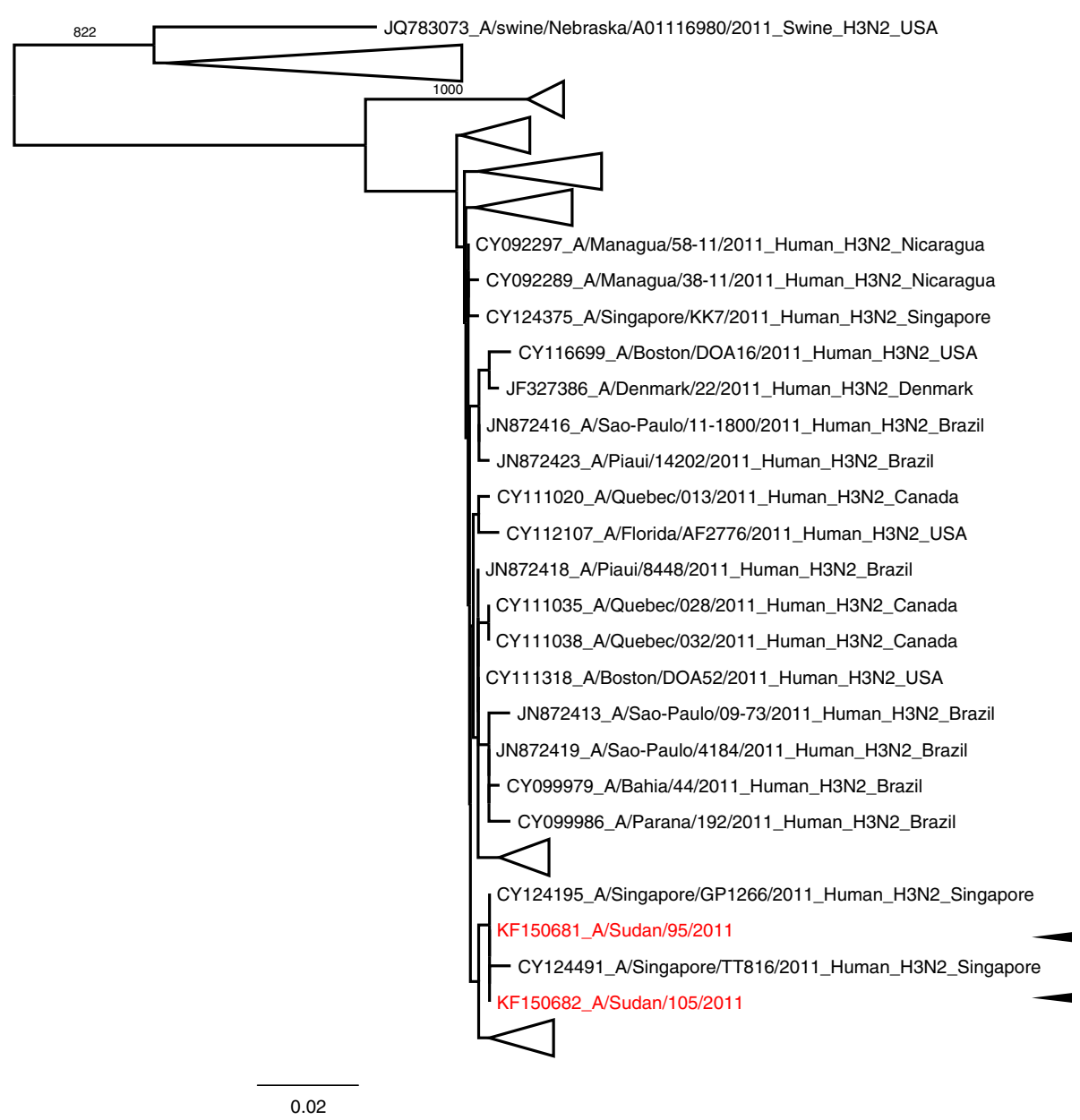

Figure 2 Phylogenetic tree of HA3 gene of influenza A strains from Sudan. Tree was constructed from representative strains detected in 2011. Some branches were collapsed for clarity. The actual tree with all the strains can be viewed in Additional file 5 and the strains in the expanded branches are indicated by green lines. Bootstrap values (1000 times) are shown at the nodes. Arrowheads indicate strains from Sudan.

\section{Methods}

\section{Study site}

The study was conducted in the Khartoum State of Central Sudan, which had a population of $5,274,321$ at the time of the 2008 national census [14]. Patients, including hospitalized patients and children seen at the emergency department in Khartoum Hospital, were recruited between January to March in 2010 and in the same months in 2011.

\section{Data collection}

Through a structured questionnaire, information on age, occupation, gender, onset of disease, clinical symptoms, response to antibiotics, influenza vaccination and place of sample collection, was recorded for each patient during the medical consultation.

\section{Collection of specimens}

A throat swab sample was obtained from each patient by inserting sterile nylon swab (Regular Flocked swab, Cat.
No. 520CS01, Copan Diagnostics Inc., Murrieta, Calif, USA) and rubbing the tonsils and the posterior wall of the pharynx. Samples collected were transported in an ice pack on the same day of collection to the laboratory of the Department of Virology, Central Laboratory (Ministry of Science and Technology) and stored at $-80^{\circ} \mathrm{C}$ until tested.

The frozen aliquots were transported on dry ice to the Department of Virology, Institute of Tropical Medicine, Nagasaki University, Japan, where one aliquot per enrolled patient was tested for the presence of influenza virus by means of multiplex-real time RT-PCR.

\section{RNA extraction}

Total RNA was extracted by using the QIAamp Viral RNA Mini spin according to the protocol of the manufacturer (Qiagen, Germany). Briefly, $140 \mu \mathrm{l}$ of throat swab sample was added to $560 \mu \mathrm{l}$ buffer AVL containing carrier RNA, and then incubated at room temperature 


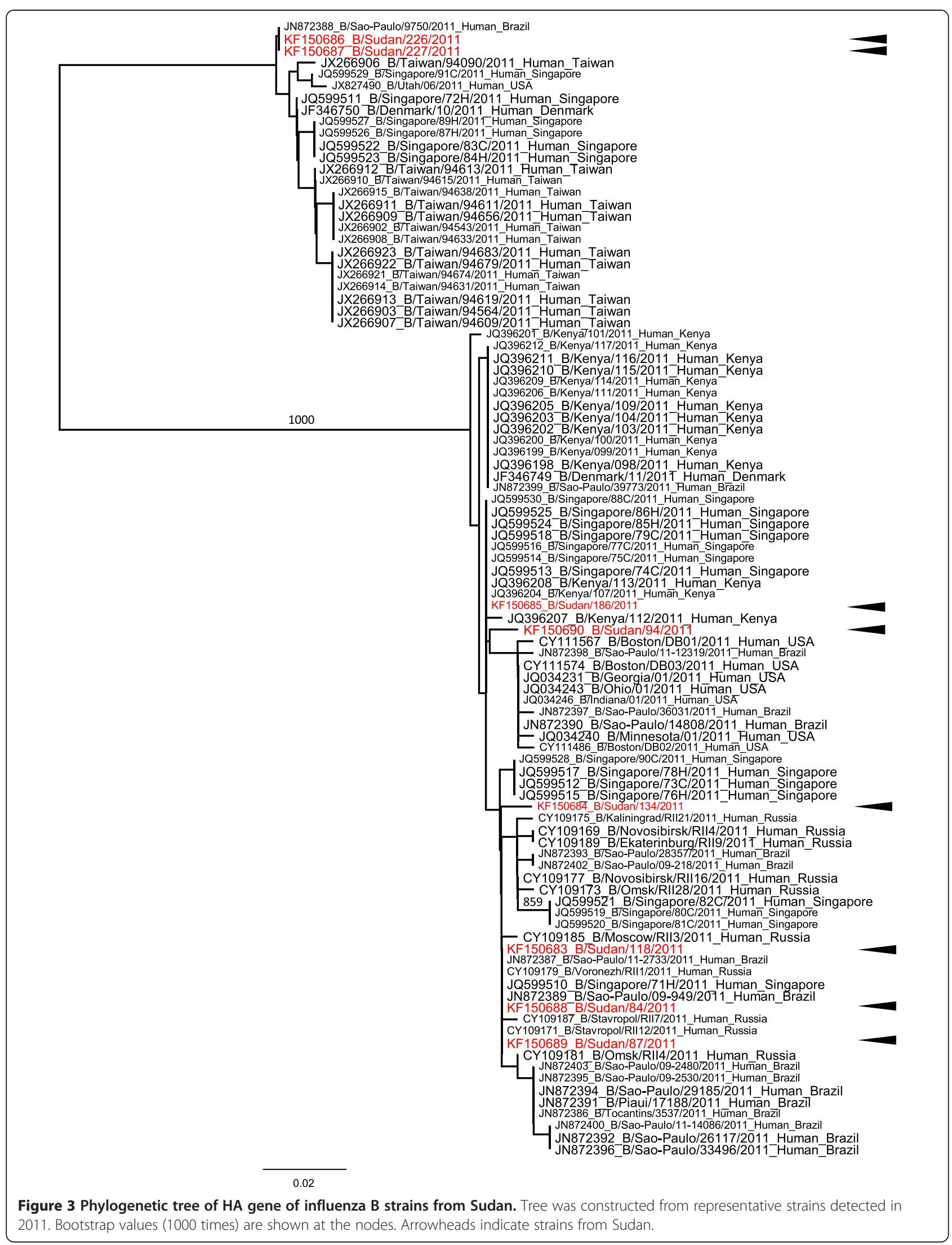


Table 6 Primers and probes used in this study*

Primer Name Sequence ( $5^{\prime}$ to $\left.3^{\prime}\right)$

Primers for real time RT-PCR

\section{Set 1}

Inf A- F

$\operatorname{lnf} A-R$

Inf A- probe

InfB-F

InfB-R

InfB-probe

FluC-F

FluC-R

FluC-probe

RNase P-F

RNaseP-R

RNaseP-probe

Set 2

RSV-F

RSV-R

RSV- probe

hMPV-F

hMPV-R

hMPV-Probe

Rhino-F

Rhino-R

Rhino-Probe

Adeno-F

Adeno-R

Adeno-Probe

Set 3

SW InfA -F

$S W$ InfA-R

SW InfA-Probe

HA3-115-F

HA3-375-R

HA3-208-Probe

H1-F

$\mathrm{H} 1-\mathrm{R}$

H3-F

$\mathrm{H} 3-\mathrm{R}$

$\operatorname{lnf} B-F$

$\operatorname{lnf} B-R$

GACCRATCCTGTCACCTCTGAC

ATCGGATCCTCAACTCACTCTT

TGCATTAAAAGCGGATTCGTT

AGATTTGGACCTGCGAGCG

GAGCGGCTGTCTCCACAAGT

CATTGTTTGACCGGCCCCATAA

TGGACAGGGTGTGAAGAGC

CAAAGTAGTCGGTCCCATCC

GTGRGCTGGGTITTCATTTGGTC

\section{Primers for sequence}

GCTATTTCTGGGGTGAATCT

AGCAAAAGCAGGGGATAATTC

TGCCTGAAACCGTACCAACC

AGCAGAAGCGTTGCATTTTC

ACCAGCAATAGCTCCGAAGA
AGGGCATTYTGGACAAAKCGTCTA

TAMRA-TGCAGTCCTCGCTCACTGGGCACG-BHQ2

NS

TGACCAAATTGGGATAAGACTC

FAM-CTCGAATTGGCTTTGRATGTCCTTCAT-BHQ1

NS

RNase $P$

CY5-TTCTGACCTGAAGGCTCTGCGCG-BHQ3

GCCAAAAAATTGTTTCCACAATA

L

[16]

TCTTCATCACCATACTITTCTGTTA

FAM-TCAGTAGTAGACCATGTGAATTCCCTGCA-BHQ1

AACCGTGTACTAAGTGATGCACTC

N

[17]

Cal Flour Orange560-CTITGCCATACTCAATGAA CAAA CT-BHQ1

5'- UTR

[18]

TAMRA-TCCTCCGGCCCCTGAATG-BHQ2

GCCCCAGTGGTCTTACATGCACATC

$\mathrm{H}$

GCCACGGTGGGGTTTCTAAACTT

Quasar670-TCGGAGTACCTGAGCCCGGGTCTGGTGCA-BHQ2

GCACGGTCAGCACTTATYCTRAG

$\mathrm{Np}$

[15]

HEX-CYACTGCAAGCCCA“T"(BHQ1)ACACACAAGC AGGCA

GCTACTGAGCTGGTTCAGAGTTC

H3

[19]

GAAGTCTTCATTGATAAACTCCAG

FAM-CTATTGGGAGACCCTCATTGTGATGG-BHQ1

AGCAAAAGCAGGGGAAAATAA

H1

[20]

H3

[20]

H3

[21]
Reference

[15]

his study

*Abbreviations: $M$ Matrix, NS Nonstructural, RNase $P$ Ribonuclease $P, L$ L protein, $N$ nucleocapsid protein, $N p$ nucleoprotein, UTR untranslated region, $H$ hexon protein, $H 1$ haemagglutinin subtype $1, H 3$ haemagglutinin subtype 3. 
for 10 minutes. Subsequently, $560 \mu \mathrm{l}$ of ethanol (96$100 \%)$ was added to the sample after which $630 \mu \mathrm{l}$ of the resulting solution was applied to a column. A volume of $500 \mu \mathrm{l}$ of AW1 and AW2 was added for washing and the nucleic acids were eluted with $60 \mu \mathrm{l}$ AVE buffer and stored at $-80^{\circ} \mathrm{C}$ until used.

\section{Real-time RT-PCR}

Real-time one step RT-PCR was done to detect viral RNA by using a commercial kit following the manufacturer's instructions (One-Step Real-Time RT-PCR Master Mixes Kit, Invitrogen, USA). Multiplex real-time RT-PCR was carried out by using 3 primer/probe sets as shown in Table 6 (set 1: Inf A [15]; Inf B [16]; Flu C [this study] and RNase P [15]; set 2: RSV [16], hMPV [17], Rhino [18] and Adeno [16]; set 3: SW Inf A [15] and HA3 [19]. With the primer/probe set 1, RNaseP was used as an internal control and real-time PCR was carried out following the protocol (but with modification for multiplex procedure) provided by Centers for Disease Control and Prevention, USA (CDC) [15]. The realtime PCR master mix for one reaction was prepared as follows: $4 \mu \mathrm{l}$ of $5 \mathrm{X}$ PCR reaction mix (consisting of a proprietary buffer system, $\mathrm{MgSO}_{4}$, dNTPs ,and stabilizers), $6 \mu \mathrm{l}$ of primer/probe, $1 \mu \mathrm{l}$ of $1 \mathrm{U}$ enzyme mix, $5.5 \mu \mathrm{l}$ of molecular grade water, $0.5 \mu \mathrm{l}$ of $10 \mathrm{X} \mathrm{ROX}$ and $3 \mu \mathrm{l}$ of total RNA $(90.3 \mathrm{ng} / \mu \mathrm{l})$. The final volume was $20 \mu \mathrm{l}$ for a single reaction. The reaction was performed in an automated 7500 real-time PCR (AB Applied Biosystems, USA). The thermal cycling conditions were 15 minutes at $50^{\circ} \mathrm{C}$ for reverse transcription, 2 minutes at $95^{\circ} \mathrm{C}$ for initial denaturation and 45 cycles of $15 \mathrm{sec}-$ onds at $95^{\circ} \mathrm{C}$ for denaturation and 45 seconds at $60^{\circ} \mathrm{C}$ for annealing and extension. A sample whose growth curve crossed the threshold line within 40 cycles $(\mathrm{Ct}<$ 40) was considered as positive. For identifying influenza A (H1N1) pdm09, positive results must be obtained with InfA in set 1 and SW Inf A in set 3 primer/probe.

\section{Virus isolation}

Throat swabs samples found positive for influenza viruses by real time RT-PCR underwent viral culture. Samples were first clarified by using syringe filter $(0.22 \mu \mathrm{m})$. A $500 \mu \mathrm{l}$ volume of each sample was then inoculated into corresponding $25 \mathrm{~cm}^{2}$ cell culture flask containing confluent Madin Derby canine kidney cells (MDCK), provided by the Department of Virology, Institute of Tropical Medicine, Nagasaki University, Japan. These inoculated cells were maintained in minimal essential medium (MEM) without fetal bovine serum but with trypsin $(0.25 \mathrm{mg} / \mathrm{ml})$, incubated at $37^{\circ} \mathrm{C}$ for 7 days, and examined daily for cytopathic effect (CPE). Multiplex RT- real-time PCR for influenza viruses types $\mathrm{A}, \mathrm{B}$ and $\mathrm{C}$ was then carried out as described above on RNA extracted from the infected culture fluid to confirm CPE.

\section{Sequence and phylogenetic analysis}

Reverse transcription was performed on extracted RNA by using Superscript III Reverse Transcriptase (Invitrogen) and random hexamers, following RNA denaturation at a temperature of $95^{\circ} \mathrm{C}$ over a period of $5 \mathrm{~min}$. PCR was conducted by using TaKaRa LA Taq DNA polymerase (TaKaRa Bio, Inc. Otsu, Japan) with primers targeting the HA gene of influenza A virus H1 [20], influenza A virus $\mathrm{H} 3$ [20] and influenza B virus [21], respectively (Table 6). In influenza A virus H1 type, the 699 bp corresponding to 461-1159 nts in the segment 4 of strain A/ Puerto Rico/8/34(H1N1) (GenBank:NC_002017) region was used to build the phylogenetic tree. In influenza A virus $\mathrm{H} 3$ type and in influenza $\mathrm{B}$ virus, the $480 \mathrm{bp}$ corresponding to 115-594 nts in the segment 4 of $\mathrm{A} / \mathrm{New}$ York/392/2004(H3N2) (GenBank:NC_007366), and the 260 bp corresponding to 1332-1591 nts in the segment 4 of strain B/Lee/40 (GenBank:NC_002207) were used, respectively. The sequences were aligned by MAFFT version 7.023b [22] with other influenza strains isolated in 2011, obtained from the influenza virus resource at the National Center for Biotechnology Information [23]. Phylogenetic trees were constructed by neighbor-joining method [24] using clustal $\times 1.83$ [25] Trees were drawn by FigTree version 1.4.0 [26]. For influenza virus types $\mathrm{A}$ $\mathrm{H} 1, \mathrm{AH} 3$, and $\mathrm{B}$, the number of strains used to build the phylogenetic trees was 856,603 , and 96 respectively.

\section{Ethical review}

The study was approved by the Ethical Review Committee (ERC) of the Ministry of Health Khartoum State, Sudan. Informed consents were obtained from adult patients, or from parents or legal guardians of children.

\section{Additional files}

Additional file 1: Fasta format of nucleotide sequence of HA1 gene of different strains of influenza A virus (found in GenBank and reported in this study).

Additional file 2: Fasta format of nucleotide sequence of $\mathrm{HA} 3$ gene of different strains of influenza A virus (found in GenBank and reported in this study).

Additional file 3: Fasta format of nucleotide sequence of HA gene of different strains of influenza B (found in GenBank and reported in this study).

Additional file 4: Actual phylogenetic tree of HA1 gene showing all influenza $A$ virus strains.

Additional file 5: Actual phylogenetic tree of HA3 gene showing all influenza $A$ virus strains.

Competing interests

Authors have no competing interests to declare. 


\section{Authors' contributions}

KAE did the sample collection, virus isolation, multiplex real-time RT-PCR, and drafted the manuscript. TN designed the experiments for sequence and did the phylogenetic analysis. TK designed the primers for detecting influenza C virus, gave some suggestions for virus isolation and supervised the work in multiplex real-time RT-PCR. CCB helped in the analysis of data and worked in the preparation and edition of the manuscript. ARMEH, IME and EAGK contributed to the conception and design of the study and helped in the drafting of the manuscript. KM contributed to the conception and design of the study, the drafting of the manuscript and the work on virus isolation. All authors read and approved the final manuscript.

\section{Acknowledgements}

We thank Khartoum Hospital for allowing us to collect throat swab samples from patients. This work was funded by the Central Laboratory, Ministry of Science and Technology (MSI), Khartoum, Sudan; Ministry of Education, Culture and Sports, Science and Technology of Japan (MEXT); Global COE program, MEXT, Japan; Japan Initiative for Global Research Network on Infectious Diseases(J-GRID).

\section{Author details}

${ }^{1}$ Central Laboratory, Ministry of Science and Technology, P.O. Box 7099, Khartoum, Sudan. ${ }^{2}$ Department of Virology, Institute of Tropical Medicine, Nagasaki University, Nagasaki 852-8523, Japan. ${ }^{3}$ Department of Molecular Epidemiology, Institute of Tropical Medicine, Nagasaki University, Nagasaki 852-8523, Japan. ${ }^{4}$ Animal Resources Research Corporation, P.O. Box 610, Khartoum, Sudan. ${ }^{5}$ Department of Microbiology and Parasitology, Faculty of Medicine, University of Khartoum, P.O. Box 8067, Khartoum, Sudan. 'Institute of Endemic Diseases, University of Khartoum, P.O. Box 45235, Khartoum, Sudan.

\section{Received: 20 July 2013 Accepted: 21 October 2013}

Published: 25 October 2013

\section{References}

1. Greenberg SB: Respiratory viral infections in adults. Curr Opin Pulm Med 2002, 8:201-208.

2. Hall CB: Respiratory syncytial virus and parainfluenza virus. N Engl J Med 2001, 344:1917-1928.

3. Feikin DR, Ope MO, Aura B, Fuller JA, Gikunju S, Vulule J, Ng'ang'a Z, Njenga MK, Breiman RF, Katz M: The population-based burden of influenzaassociated hospitalization in rural western Kenya, 2007-2009. Bull World Health Organ 2012, 90:256-263A.

4. Steffen C, Debellut F, Gessner BD, Kasolo FC, Yahaya AA, Ayebazibwe N, Bassong O, Cardoso Y, Kebede S, Manoncourt S, Vandemaele KA, Mounts AW: Improving influenza surveillance in sub-Saharan Africa. Bull World Health Organ 2012, 90:301-305.

5. Salim AR: Hong Kong influenza in the Sudan. Bull World Health Organ 1971, 44(5):713-716

6. Steffen C, Diop OM, Gessner BD, Hacen MM, Hassar M, Katz MA, Miller MA, Paget WJ, Schoub BD, Vernet G, Ndumbe PM: Afriflu - international conference on influenza disease burden in Africa, 1-2 June 2010, Marrakech, Morocco. Vaccine 2011, 29:363-369.

7. WHO: Recommended composition of influenza virus vaccines for use in the 2013-14 northern hemisphere influenza season. [http:/www.who.int/ influenza/vaccines/virus/recommendations/201302_recommendation.pdf]

8. WHO: Recommended composition of influenza virus vaccines for use in the 2013 southern hemisphere influenza season. [http://www.who.int/ influenza/vaccines/virus/recommendations/201209_recommendation.pdf]

9. Expanded immunization program in Sudan (Arabic). [http://www. episudan.info]

10. Viboud C, Alonso WJ, Simonsen L: Influenza in tropical regions. PLoS Med 2006, 3:e89.

11. Akinloye OM, Rönkkö E, Savolainen-Kopra C, Ziegler T, Iwalokun BA, Deji-Agboola MA, Oluwadun A, Roivanen M, Adu FD, Hovi T: Specific viruses detected in Nigerian children in association with acute respiratory disease. J Trop Med 2011, 2011:690286.

12. Salih MA, Herrmann B, Grandien M, El Hag MM, Yousif BE, Abdelbagi M, Mårdh PA, Ahmed H: Viral pathogens and clinical manifestations associated with acute lower respiratory tract infections in children of the Sudan. Clin Diagn Virol 1994, 2(3):201-209.
13. Kim C, Ahmed JA, Eidex RB, Nyoka R, Waiboci LW, Erdman D, Tepo A, Mahamud AS, Kabura W, Nguhi M, Muthoka P, Burton W, Breiman RF, Njenga MK, Katz MA: Comparison of nasopharyngeal and oropharyngeal swabs for the diagnosis of eight respiratory viruses by real-time reverse transcription-PCR assays. PLoS One 2011, 6(6):e21610.

14. 5th Sudan population and housing census - 2008, priority results submitted to the Presidency by Population Census Council (2009). [http://southsudaninfo.net/wp-content/uploads/reference_library/reports/ 5th_sudan_census26_april_2009.pdf]

15. CDC Protocol of real time RT-PCR for influenza $A(\mathrm{H} 1 \mathrm{~N} 1)$. [http://www. who.int/csr/resources/publications/swineflu/realtimeptpcr/en/index.html]

16. Lieberman D, Lieberman D, Shimoni A, Keren-Naus A, Steinberg R, ShemerAvni Y: Identification of respiratory viruses in adults: nasopharyngeal versus oropharyngeal sampling. J Clin Microbiol 2009, 47:3439-3443.

17. Mackay IM, Jacob KC, Woolhouse D, Waller K, Syrmis MW, Whiley DM, Siebert DJ, Nissen M, Sloots TP: Molecular assays for detection of human metapneumovirus. J Clin Microbiol 2003, 41:100-105.

18. Gunson RN, Collins TC, Carman WF: Real-time RT-PCR detection of 12 respiratory viral infections in four triplex reactions. J Clin Virol 2005, 33:341-344.

19. Schweiger B, Zadow I, Heckler R, Timm H, Pauli G: Application of a fluorogenic PCR assay for typing and subtyping of influenza viruses in respiratory samples. J Clin Microbiol 2000, 38:1552-1558.

20. National Institute of Infectious Diseases (NIID) Japan: Influenza Diagnostic Manual (Japanese). 2nd edition. Japan: Infectious Diseases Surveillance Center; 2012.

21. Annual Report: 2011/2012 (covering the period from September 16, 2011 to September 15, 2012 of the project "Developing Sustainable Influenza Surveillance Network"). Mongolia: National Influenza Center, National Center of Communicable Diseases, Ministry of Health:p.138 [http://www.flu.mn/ eng/images/stories/lavlamj/REPORT_2011-2012_English.pdf]

22. Katoh K, Misawa K, Kuma K, Miyata T: MAFFT: a novel method for rapid multiple sequence alignment based on fast Fourier transform. Nucleic Acids Res 2002, 30:3059-3066

23. Bao Y, Bolotov P, Dernovoy D, Kiryutin B, Zaslavsky L, Tatusova T, Ostell J, Lipman D: The influenza virus resource at the national center for biotechnology information. J Virol 2008, 82:596-601.

24. Saitou N, Nei M: The neighbor-joining method: a new method for reconstructing phylogenetic trees. Mol Biol Evol 1987, 4:406-425.

25. Felsenstein J: PHYLIP - Phylogeny inference package (Version 3.2). Cladistics 1989, 5:164-166.

26. Rambaut A: Molecular evolution, phylogenetics and epidemiology. 2009 [http://tree.bio.ed.ac.uk/software/figtree/]

doi:10.1186/1743-422X-10-312

Cite this article as: Enan et al: Survey of causative agents for acute respiratory infections among patients in Khartoum- State, Sudan, 20102011. Virology Journal 2013 10:312.

\section{Submit your next manuscript to BioMed Central and take full advantage of:}

- Convenient online submission

- Thorough peer review

- No space constraints or color figure charges

- Immediate publication on acceptance

- Inclusion in PubMed, CAS, Scopus and Google Scholar

- Research which is freely available for redistribution 